\title{
OS CONSELHEIROS DO TRIBUNAL DE CONTAS DO ESTADO DO PARANÁ: REDES SOCIAIS, NEPOTISMO E INFLUÊNCIA POLÍTICA ${ }^{1}$
}

Fernando Marcelino Pereira ${ }^{2}$

- Enviado em 13/01/2016

- Aprovado em 15/02/2016

O Tribunal de Contas do Paraná, como objeto de pesquisa específico até o momento não foi explorado pelas Ciências Sociais. E, diferentemente do Executivo e do Legislativo, o Tribunal de Contas é pouco exposto a pressões da opinião pública, apesar de ser popularmente conhecido como local de coagulação de disputas e deliberações acerca de aspectos relevantes da vida política estadual. É verdade que estudos recentes têm contribuído para uma compreensão mais abrangente sobre diferentes aspectos e mudanças relacionadas ao perfil e carreira nos diversos níveis políticos. Podemos afirmar que existe certa tradição de estudos que se debruçam na temática da composição do Poder Legislativo, Executivo e Judiciário, estudos sobre a burocracia do Estado do Paraná, todavia percebemos que as instituições de controle, entre as quais se destaca o Tribunal de Contas, são pouco pesquisadas. Muito pouco se sabe sobre o poder que o Tribunal de Contas exerce sobre os outros poderes e sobre a sociedade, quem são seus conselheiros, como são escolhidos, como tomam decisões e como agem dentro do Tribunal.

O objetivo de nossa pesquisa de doutorado é abrir a caixa preta desse espaço, reforçar e refutar estudos sobre o arranjo da estrutura de classe dominante paranaense. Por um lado, delinear o

\footnotetext{
${ }^{1}$ Pesquisa de doutorado em andamento sob a orientação do Professor Doutor Ricardo Costa de Oliveira no Programa de Pós-graduação em Sociologia da UFPR.

${ }^{2}$ Graduado em Relações Internacionais pela UNICURITIBA, Mestre em Ciência Política e Doutorando em Sociologia pela UFPR. Membro do Núcleo de Estudos Paranaenses (NEP). Endereço eletrônico: fernandomarcelinopereira@gmail.com
} 
perfil e a trajetória dos conselheiros do TCE-PR. Por outro lado, analisar como a estrutura do TCEPR é atravessada por capitais familiares em seu corpo funcional - auditores, servidores comissionados, efetivos e aposentados. Este projeto tem a orientação do Dr. Ricardo Costa de Oliveira, pois concentra investigações no papel dos conselheiros do Tribunal de Contas na articulação do Poder do Estado do Paraná. O estudo inscreve-se na corrente de estudos que tem por preocupação o estudo sobre quem são as elites políticas, sua estrutura de parentesco, genealogia e nepotismo, com ênfase na trajetória política, social e familiar os conselheiros do Tribunal de Contas do Estado do Paraná desde sua fundação em 1947.

Em 2017 o TCE-PR faz 70 anos. O Tribunal foi criado em 2 de junho de 1947, através do Decreto-Lei estadual n ${ }^{\circ} 627$ do então governador do Estado, Moysés Lupion. O corpo deliberativo era por um corpo instrutivo, uma representação da Secretária da Fazenda do Estado e cinco juízes. Foram escolhidos por Lupion os juízes Raul Vaz, Daniel Borges dos Reis, Brasil Pinheiro Machado, Raul Viana e Caio Graccho Machado Lima. Quase todos eram ligados ao então primeiro governo Lupion, que começara em 12 de março de 1947, menos de três meses antes do Decreto de fundação do Tribunal. Raul Vaz era diretor do jornal lupionista O Dia. No Governo Lupion ocupou os cargos de Diretor Geral do Departamento de Municipalidade e secretário estadual do Interior e Justiça. Caio Graccho Machado de Oliveira Lima, filho de Vicente Machado, foi jornalista e diretor do jornal O Dia. Raul Viana era da Secretaria de Agricultura, Indústria e Comércio de Lupion e diretor do jornal "trabalhista" Diário Popular, impresso nas oficinas do jornal O Dia. Daniel Borges dos Reis foi secretário do Palácio do Governo de Lupion. O Interventor Federal do Paraná Brasil Pinheiro Machado foi derrotado por Lupion nas eleições de 1947 e foi indicado para Juiz do TC. Em 14 de julho de 1947 foi eleito presidente Raul Vaz (fato que se repetiria por mais 15 vezes em sua carreira) e Daniel Borges dos Reis à vice-presidência.

Nesses primeiros anos da Corte, a grande preocupação foi estrutura-la para exercer seu papel fiscalizador. Vêm desta época as primeiras instruções para a análise dos processos e para a organização das atribuições do Tribunal de Contas. Durante as décadas de 1950 e 1960 o Tribunal sofreu alterações em sua organização e competência. O número de juízes - que passaram a ser chamados ministros - subiu de cinco para sete, com igual número de suplentes. Também foi criada a vaga de auditor, com sete vagas.

Até a promulgação da Constituição Federal de 1967, o TCE-PR detinha, entre outras competências, a atribuição de acompanhar a execução orçamentária, registrar previamente as despesas e os contratos, além de julgar as contas dos responsáveis por bens e dinheiro públicos. 
Entretanto, o então governador Paulo Pimentel manteve a competência de análise a priori dos gastos do dinheiro público. Conforme Pimentel, o registro prévio dos gastos "para mim não atrapalhava nada. Pelo contrário, me dava tranquilidade, pois quando a despesa era paga ou quando as obras eram iniciadas, tudo já havia sido examinado pelo TC”. Apenas depois, a partir de 1971, houve uma significativa alteração na forma de atuação do Tribunal de Contas, passando de um controle preventivo, que precedia às contratações públicas, para um controle repressivo, posterior à concretização do ato pela Administração. Com a promulgação da Constituição Federal de 1988, os Tribunais de Contas ganharam competências e foram fortalecidos. O modelo de controle externo a posteriori foi mantido pela Constituição Federal de 1988 e ampliou-se o campo de atuação do Tribunal, recebendo poderes para exercer a fiscalização contábil, financeira, orçamentária, operacional e patrimonial. Houve alargamento no rol daqueles que devem prestar contas, abrangendo pessoas físicas e jurídicas, públicas ou privadas, todas as entidades da administração direta e indireta, incluindo as fundações e sociedades instituídas e mantidas pelo poder público.

Atualmente o TCE-PR possui amplas atribuições e provoca impactos significativos no Poder Executivo do Governo Estadual, na Assembleia Legislativa, no Judiciário e em todo campo das políticas públicas dos 399 Municípios do Paraná, empresas e outras esferas da vida cotidiana da sociedade paranaense. O TCE-PR fiscaliza as contas do Governador, dos chefes da Assembleia Legislativa, Tribunal de Justiça, Ministério Público, Controladoria Geral, Defensoria Pública e do próprio Tribunal de Contas, além dos prefeitos e presidentes de câmaras municipais. Também fiscaliza empresas estatais e mistas (Sanepar, Copel, Compagás, etc), secretarias estaduais e municipais, Porto de Paranaguá, autarquias, universidades estaduais, fundos, fundações, entidades do terceiro setor, entre outros órgãos. São mais de 2 mil entes públicos e privados que são fiscalizados pelo TCE-PR.

O corpo diretivo e operacional do TCE-PR é integrado pelos conselheiros, auditores e procuradores do Ministério Público de Contas, dispondo de uma estrutura técnica com pouco mais de 600 funcionários. O corpo deliberativo do TCE-PR é um colegiado de Conselheiros, o Tribunal Pleno, formado por sete membros com cargo vitalício. Quatro deles são escolhidos pela Assembleia Legislativa e três pelo chefe de governo. Das cadeiras do governo estadual, apenas uma é de livre escolha. As outras duas vagas estão vinculadas à lista tríplice, uma do Ministério Público e outra da carreira de auditores. 
Nosso estudo tem como objeto de pesquisa sobre os conselheiros, pois concentram o poder político do Tribunal e possuem vantagens consideráveis: tem as mesmas garantias, prerrogativas, impedimentos, vencimentos e vantagens dos desembargadores do Tribunal de Justiça. Os conselheiros do TCE-PR, como os altos funcionários do Estado, estão situados junto com desembargadores, por força de dispositivo constitucional. $\mathrm{O}$ universo da pesquisa compreende os 31 conselheiros que integraram o Tribunal Pleno entre 1947 e 2016. São eles: Raul Vaz, Raul Viana, Caio Graccho Machado Lima, Brasil Pinheiro Machado, Daniel Borges dos Reis, Eugênio José de Souza, Lauro Rego Barros, Algacyr Guimarães, Nacim Bacilla Neto, Leônidas Hey de Oliveira, José Isfer, Antônio Ferreira Rüppel, Rafael Iatauro, João Féder, Armando Queiróz de Moraes, Cândido Manuel Martins de Oliveira, João Olivir Gabardo, João Cândido Ferreira da Cunha Pereira, Nestor Baptista, Quielse Crisóstomo da Silva, Artagão de Mattos Leão, Henrique Naigeboren, Heinz Georg Herwig, Fernando Augusto Mello Guimarães, Caio Marcio Nogueira Soares, Hermas Eurides Brandão, Maurício Requião de Mello e Silva, Ivan Lelis Bonilha, José Durval Mattos do Amaral, Fábio de Souza Camargo e Ivens Zschoerper Linhares. Nossa intenção é pesquisar a origem social, trajetória e redes políticas dos conselheiros do TCE-PR. Vamos traçar o perfil social dos conselheiros (isto é, origem de classe, tipo e tamanho do patrimônio herdado ou construído, acesso a educação superior e posse de títulos escolares, habilidades profissionais, gênero, origem étnica, e outros indicadores de posição social), suas carreiras (idade de ingresso no mundo política, número de mandatos antes de chegar a posições superiores na hierarquia política, quantidade de partidos por que passou, cargos estratégicos que dirigiu, etc.) e relações de parentesco existente entre conselheiros, funcionários e os cargos comissionados, bem como a relação dos conselheiros com políticos, gestores, juízes, cartorários, empresários, entre outros, formando redes de nepotismo, favoritismo e troca de favores. Analisaremos a rede social dos conselheiros com parentes, amigos e assessores conectados em esquemas de poder. Relações pessoais e de amizade construídas no decorrer de anos, algumas familiares, outras oriundas da formação profissional, e outras ainda constituídas por vínculos de trabalho e afinidade política, constituem essa rede que abrange e integra diversos campos da vida social, tanto dentro quanto fora do Estado. Em suma, pretende-se definir e analisar as redes sociais, familiares, profissionais e políticas dos conselheiros.

Utilizamos o método prosopográfico de biografia coletivas, de forma quantitativa, visando dar o sentido às ações políticas do grupo, visando entender possíveis mudanças sociais, políticas e culturais. O referencial teórico, que instrumentalizou o enfoque sociológico, tomou como ponto de partida a relação entre os conceitos de "espírito de família", "campo", "habitus" e "trajetória" de 
Pierre Bourdieu, pois é justamente no espaço do campo onde podem ser detectadas as relações de poder e vínculo familiar. Este estudo, ao montar o complexo tecido relacional dos conselheiros, permitirá analisar a dinâmica do poder do TCE-PR, sua inserção no ambiente político, identificar detalhadamente os padrões de relacionamento entre os Conselheiros, suas mudanças no tempo, conexões de nepotismo e a presença de seus membros na esfera política.

A principal contribuição de analisar o perfil e a rede de poder em torno desta "elite políticoconselheira" é acrescentar o conhecimento sobre o nepotismo e a articulação da classe dominante no Estado do Paraná. Este estudo, ao montar o complexo tecido relacional dos conselheiros, permitirá analisar a dinâmica do poder do TCE-PR, sua inserção no ambiente político, identificar os padrões de relacionamento entre os Conselheiros, suas mudanças no tempo, conexões de nepotismo e a presença de seus membros na esfera política.

As fontes para o estudo sobre os conselheiros são variadas. Aqueles que passaram por outros cargos públicos ou integram famílias tradicionais costumam ter mais informações disponíveis. Também são de grande valia a genealogia paranaense de Francisco Negrão, o silêncio dos vencedores de Ricardo Costa de Oliveira, entre outras obras genealógicas. Quanto à pesquisa qualitativa do objeto empírico constam documentos referentes ao universo do Tribunal de Contas do Paraná - dezenas de edições da revista do TC, súmulas, decisões, materiais informativos diversos, etc - que serão coletados no próprio Tribunal de Contas. Também conta-se com dados referentes ao portal da transparência, o sítio virtual do TC e notícias de jornal. Outras fontes também serão exploradas a partir de pesquisa cartorial e análise de processos e investigações criminais (do CNJ, GAECO e TJ-PR). Por fim, pretendemos entrevistar alguns conselheiros e funcionários do TCE-PR, assim como jornalistas, políticos e assessores do Poder Legislativo e Executivo, Juízes e Desembargadores do Poder Judiciário. 